\title{
A LINGUAGEM DE APRENDIZES: SINGULARIDADE DE CASOS
}

Reny Maria Gregolin-Guindaste ${ }^{*}$

\section{Introdução $^{* *}$}

objetivo deste artigoé noticiar alguns fatos de linguagem observados durante o acompanhamento longitudinal de casos-problema de alfabetização. Estes fatos são achados de casos que permitem a visibilidade de dados, que não são simplesmente evidências ou exemplos, se assumida uma projeção do que propõe Coudry (1996).

Primeiramente apresentarei as circunstâncias que oportunizaram o acesso aos casos e dados e farei considerações sobre a escolha teórica. Em seguida citarei alguns casos que apresentam variabilidade e singularidade, alguns já estudados, outros à espera de pesquisa, e, finalmente, comentarei sobre a avaliação de um caso muito singular: P.H.

Não tratarei aqui dos casos que apresentam regularidades, isto é, ocorrência dos mesmos dados-achado em muitos sujeitos.

* Universidade Federal do Paraná

** Agradeço a Lígia Negri e Iara Bemquerer Costa pela primeira leitura e pelos comentários. Usando frase feita, é óbvio que os erros são meus. 


\section{Circunstâncias}

Nas atividades desenvolvidas no projeto de extensão "Diagnóstico e acompanhamento longitudinal de casos-problema de alfabetização", profissionais de diferentes áreas - neuropediatra, psicólogo, assistente social, lingüista e pedagogo ${ }^{\prime}$ - buscam explicitar e indicar diretrizes à escola para casos-problema de crianças em fase inicial de escolaridade. Estes casos-problema, que apresentam origem e natureza diversas, são apontados primeiramente pela escola e encaminhados para avaliação. Após exame neurológico, são feitos testes psicológicos clássicos e avalia-se o conhecimento de escrita que a criança apresenta, através de produção solicitada. Em alguns casos, faz-se necessária a avaliação da linguagem oral para diagnosticar a competência lingüística e o domínio de linguagem da criança. Quando a criança apresenta problemas, justamente pelo pouco, ou por nenhum conhecimento de escrita, não há como avaliar sua capacidade através desta modalidade. Nesse caso, a linguagem oral passa a ser investigada e nos casos-problema os achados passam a ser encontrados e investigados. Os dados-achado ocorrem em casos singulares. Embora sem a padronização, ainda cara à ciência médica, a investigação da oralidade permite localizar o nível lingüístico afetado e diagnosticar a capacidade lingüística da criança com mais segurança do que os testes psicológicos.

Quando os diversos profissionais concluem seus diagnósticos, é feita entrevista com os pais da criança. Os casos-problema de ordem emocional são encaminhados para acompanhamento psicológico por profissionais da UFPR e os casos-problema de aquisição de linguagem escrita são acompanhados individualmente por bolsistas que, orientados para desenvolverem atividades dialógicas de linguagem, oportunizam a exibição dos problemas, para análise lingüística e posterior conscientização e superação. Este trabalho é desenvolvido na escola de origem, onde é feita a coleta de dados que estão sendo arquivados e que permitem os achados.

I Sũo os seguintes os profissionais da UFPR que participam do projeto: Isac Bruck (neuropediatra do Departamento de Pediatria do HC), Sandra R. Baggio Muzzolon (psicóloga), Reny Maria Gregolin-Guindaste (Departamento de Lingüística), Ana Chrystina Crippa e Eduardo Kachler Meister (residentes da neuropediatria do HC), Mirian B. R. Doehmert e Maria Alice do Carmo (assistentes sociais), Maria do Carmo Taborda Ribas e Maria de Fátima Miranda (pedagogas da Escola Estadual Aline Picheth). 


\section{A ancoragem teórica}

Do ponto de vista lingüístico, estão sendo considerados: o trabalho com a linguagem enquanto atividade constitutiva do sujeito, conforme explicitada em Franchi (1977); as atitudes metodologicas dela decorrentes, tais como depreendidas de Geraldi (1991); o trabalho com a linguagem em quadros patológicos, numa projeção de Coudry (1988); a perspectiva não-tradicional de aquisição de linguagem escrita, baseada em teorias de cunho sociointeracionista, conforme explicitada em recomendações para o trabalho com a linguagem apresentada em publicações oficiais; ${ }^{2}$ trabalhos sobre alfabetização que levam em consideração os pressupostos da psicologia soviética, tais como os de Mayrink-Sabinson (1993); para análise lingüística de dados singulares, Abaurre (1996), e, para avaliação da oralidade, os trabalhos de Perrone (1992). Mais longínquos, mas não incoerentes com os trabalhos recentes citados, estão as postulações de Luria (1979), devido à concepção de cérebro como um todo funcional complexo e devido à noção de neuroplasticidade. Esta, por sua vez, é coerente com a concepção de linguagem enquanto atividade capaz de formação de novas redes neuronais, do inter para o intrapsicológico.

Para o desenvolvimento de atividades de ensino e avaliação de linguagem, somente uma perspectiva discursiva pode ser selecionada, a fim de que possa considerar a ampla constituição da significação. O mesmo ocorre com casos patológicos para que os dados sejam obtidos e para que se possa fazer intervenções precisas visando a formação da consciência do sujeito para seus próprios problemas lingüísticos. Estas duas instâncias licitam o abandono do trabalho com a linguagem tal como era feito nos moldes tradicionais. Não são mais o treinamento de um código gráfico, nem a preocupação com a medida padronizada do comportamento lingüístico, concretizados na cópia escolar e na atribuição de notas a partir da contagem de erros ortográficos, que devem estar focalizados.

O desempenho linguíístico em processo, com hipóteses respeitadas e sem o treinamento escolar tradicional, dá lugar aos achados. São os bloqueios decorrentes de atitudes escolares repressoras, que exigem da criança domínio completo das convenções ortográficas desde o início do processo escolar, que impedem a ocorrência de muitas hipóteses sobre a língua e velam os achados em muitos casos.

2 Trata-se do Currículo Básico para escolas públicas do Paraná (1990) e Cadernos do Ensino Fundamental, n. 2, 6 e 8 (1992). 
Em casos com problemas leves e moderados, a criança que é produto de alfabetização tradicional cristaliza na memória um recorte restrito de linguagem, copia tudo, acerta palavras previamente treinadas em ditados ou até em escrita espontânca, escreve frases feitas previamente treinadas e os problemas de aquisição de escrita ficam velados com essa pseudoprodução. São falsos casos de crianças alfabetizadas.

Uma avaliação da escrita autônoma revelará casos-achado, os quais poderão ter aprofundamento de estudo, conforme as peculiaridades apresentadas. Assim, para fins de pesquisa permite-se, com clareza e rigor teóricos, acionar outras teorias da lingüística para fins explicativos, pois a singularidade e a variabilidade dos casos e dos dados-achado obrigam-nos ao mergulho em águas mais profundas do que permitem as teorias discursivas. É o próprio dado-achado que confirma a escolha teórica para análise e explicação de pormenores afetados em cada nível e em cada quadro. Nesse processo, peculiar nos trabalhos da neurolingüística moderna, o dado é produto da articulação de teorias sobre o objeto que se investiga durante a avaliação e acompanhamento de processos lingüistico-cognitivos.

Considerar casos diferentes e ser obrigado a convocar teorias diferentes para explicitar dados não pode ser um procedimento ingênuo do pesquisador. Considerando que os dados não são evidência empírica, e que não há pesquisa nem metodologia ateóricas, o recorte será feito conforme o que se quer investigar: Feito o recorte de estudos, têm lugar algumas experimentações, constituídas de testes não-tradicionais planejados conforme a teoria de base o permitir para confirmação dos achados.

O objetivo da experimentação é avaliar a competência em algum nível específico para verificar o que da linguagem está alterado e o que está em desenvolvimento. Os resultados obtidos auxiliam a análise lingüistica de dados de linguagem produzidos por aprendizes de escrita, cujos casos são investigados. Verifica-se, primeiramente, se neles há ou não questōes de ordem patológica envolvidas e a experimentação só tem lugar quando são verificadas alterações. Assim os achados se ampliam e passam a constituir o universo de cada pesquisa. Dados-achado em casos-achado buscam ser explicitados por uma teoria adequadamente escolhida que, pelo poder de explicitação permitido, encontra ou não plausibilidade. 


\section{Casos}

A escola adota um modelo exemplar de criança não-problema: aquela que não apresenta lentidão na aquisição da escrita, que não erra muito para escrever, que demonstra compreender e exerce a função reguladora da linguagem obedecendo ordens e regras, que apreende o discurso da escola e do professor para repetir o "jogo" escolar, que fala de vez em quando e que não é indisciplinada e faltosa.

Todos os que fogem à padronização imposta pelo senso comum escolar são diagnosticados à primeira vista como casos-problema. Nem todos apresentam problemas de natureza lingüístico-cognitiva. Muitas crianças que a escola aponta como problema não tiveram nenhuma convivência com a escrita antes de ingressar na primeira série e que demoram para interiorizar esse conhecimento, que não encontram valorização na família para essa atividade, não se interessando, conseqüentemente, por essa aquisição quando postas no coletivo da turma. Outras têm ritmo próprio, mais lento, mas com ajuda individualizada de um parceiro competente conseguem freqüentar salas regulares.

Casos como esses são acompanhados num trabalho preventivo para que a criança, com ajuda individualizada, direcionada especificamente, conforme o momento de aquisição, e conforme o conhecimento já adquirido, possa seguir o curso normal das atividades escolares. São esses casos que compõem a regularidade das 30 crianças, com dados registrados, nos anos de 1995 e 1996; a maioria demonstrou progresso considerável na aquisição da escrita e está seguindo a cscolaridade em salas regulares, embora muitas tenham obtido nos testes psicológicos clássicos desempenho abaixo da média. Esses casos regulares são encontrados principalmente nas primeiras séries quando a escola passa a ficar ansiosa com a demora ou lentidão na aquisição da escrita. É o que pode ser verificado nos três casos de aquisição de escrita acompanhados longitudinalmente por Gusso (1996). Convém lembrar que se crianças como essas não forem individualmente orientadas podem vir a ser casos-problema na série posterior.

Mas a intuição dos que convivem com crianças de história e características variadas detectaram casos, em séries mais avançadas, que depois de avaliados e acompanhados constituem casos singulares. Selecionei alguns cujos dados merecem acompanhamento e pesquisa mais aprofundada para maior explicitação dos fatos observados. 
Caso 1: o caso J.

Começarei por aquele que constituiu o objeto de estudo da tese de Pan (1995). Trata-se de um caso de seqüelas cognitivas que os neuropediatras atribuíram à privação nutricional até os dois anos. Nos primeiros encontros, a menina de 8 anos, que já havia permanecido um ano inteiro numa sala regular sem ao menos conseguir escrever o nome ou alguma letra, conseguia passar ao investigador a imagem de que não tinha problemas na oralidade. Contava com entusiasmo histórias inventadas, as quais não foram detectadas, de início, como fuga dos problemas enfrentados por J. Só mais tarde, durante avaliação da oralidade a partir dos estudos de narrativa, conforme Perrone (1992), é que ficou clara a sistematicidade com que a criança fantasiava quando não tinha elementos para recontar eventos do passado real.

J. não conseguia recontar, por exemplo, quais os acontecimentos que faziam parte da festa do dia da criança que tinha acontecido na escola e da festa na clínica. Cessava propositadamente o discurso do investigador quando este procurava as exibições das dificuldades lingüísticas de J. Fugia do tema quando tinha dificuldade para desenvolver o assunto.

INV.: Você disse que ganhou presente, comeu bolo e o que mais?

J.: Quero contar história disso aqui. Chega de pergunta. Vou gravar outra história desse livro aqui.

INV.: Como é o nome da história?

J.: Você não faz pergunta que eu conto.

Quanto ao conhecimento de escrita, J., que havia sido encaminhada para uma sala especial na qual foi flagrada copiando as vogais nas formas de imprensa e manuscritas, em maiúsculas e minúsculas, passa a distinguir, já no início do acompanhamento, o $M$ presente em Mirian, a psicóloga, também presente em Flor de Mel e em Shopping Müller, e a perceber, a partir da conscientização da percepção, a semelhança entre o $B$ de Banestado e o de Bamerindus. Apesar do ritmo próprio e do diagnóstico, J. iniciava-se na escrita. 
Este é um caso de criança com problemas cognitivos leves detectados pela escola, pelos testes psicológicos aplicados e com problemas de linguagem detectados através da análise lingüística de dados da oralidade, principalmente quanto à questão da capacidade para narrar eventos ocorridos. Mas apesar dos problemas, J. consegue localizá-los e enfrentá-los e com ajuda do investigador obtém progressos na qualidade da narrativa oral e inicia-se na escrita após 10 sessões, desenvolvendo correspondências grafema-fonema que não tinham sido observadas em dois anos de escolaridade.

Procedimento de avaliação de linguagem semelhante ao que foi feito no caso J. deve ser percorrido no caso R. No primeiro contato com a investigadora, esta perguntou a $R$. se queria entrar numa sala de aula ou se queria ficar um pouco no pátio da escola. A resposta foi "Eu quero ficar no pátio por muito, muito tempo".

Um dos primeiros episódios singulares apareceu com uma denúncia da criança para a mãe na volta da escola, de que a professora havia cortado seu cabelo. Tratava-se de uma "arte" entre colegas. Até aí o diagnóstico da criança, que com três meses de frequiência escolar não aprendeu a engendrar letras e só as conhece isoladamente, parecia ser o da criança faltosa, desinteressada, mas que tinha capacidade lingüística discursiva para elaborar o texto narrativo no passado com estrutura completa de narrativa.

Mas as invenções exageradamente fantasiosas de $R$. provocam curiosidade no pesquisador. A criança vai além da capacidade de tecer a mentira. Cria um mundo que tem feito parte de seus relatos em pelo menos três encontros consecutivos. Inventou um episódio de acidente com o namorado de uma irmã inexistente, pois sua história familiar era previamente conhecida pelo investigador. Num outro encontro o investigador perguntou-lhe se a irmã estava em casa e R. respondeu: "Ela não voltou de viagem", o que demonstra a sua capacidade de manter a coerência no discurso não pautado na realidade. Já num outro encontro, essa lógica se rompe e a irmã passa a ter apenas um ano.

Trata-se de um caso a ser estudado a partir da oralidade para que se possa diagnosticar a capacidade lingüística da criança. Como se trata de um caso em início de acompanhamento, o progresso na aquisição da escrita não foi detectado. R., com 4 meses de escolaridade, escreve apenas seqüências de letras aleatoriamente, sem nenhuma correspondência grafema-fonema. Além da análise da oralidade para verificar se as "mentiras" de R. são ou não uma forma de fuga de scus problemas, tal como procedia J., um trabalho de alfabetização não-tradicional, paralelo ao trabalho da sala de aula regular e baseado numa concepção discursiva de linguagem, está se iniciando. 
Caso 2: o caso D.

Atualmente na quinta série, o caso D. apresentou-se para avaliação há dois anos devido à falta de linguagem oral do aluno, na época cursando o início da terceira série. D. não falava nada com a professora e muito pouco com poucos colegas. Mas falava em casa com os pais. Na escola negava-se a fazer muitas atividades, embora demonstrasse capacidade para realizá-las, o que podia ser diagnosticado nas poucas amostras obtidas. Em contato com o investigador, D. só the dirigia o olhar quando solicitado a fazê-lo. Só respondia, telegraficamente, o que the cra perguntado, preferindo respostas do tipo sim/não com acenos de cabeça.

Num dos encontros, tendo respondido afirmativamente que gostava de histórias, foi convidado a escolher um livrinho. Escolheu a história de Didi, o dinossauro. Leu em voz alta, mas não respondeu às perguntas do investigador nem the dirigiu o othar quando este the perguntou o que tinha entendido da história. Foi proposto, então, que o investigador contaria a história para que D. a recontasse por escrito. Durante a narrativa oral do investigador foi perguntado a D. se ele lembrava de alguns acontecimentos.

A criança às vezes se manifestava, mas quando era pedido para que ela continuasse, cmudecia. Quando foi pedido que escrevesse, ficou bom tempo parado olhando para o caderno. Tratava-se da história de uma ema mentirosa que um dia disse a outros animais que havia botado um ovo muito grande. Quando o ovo se abriu, saiu dele um filhote de dinossauro que acompanhou a ema, até que um dia sua própria mãe apareceu e saíram juntos pela floresta deixando a ema solitária.

D. escrevcu o título e apenas o começo da história. Ficou a tremer com o lápis sobre o papel. Foi o seguinte o dado obtido:

Didi o dinossauro passeando pela floresta a ema encontrou um ovo.

No segundo encontro somente foi obtido um desenho sobre o qual não quis lalar nada. Escolheu o mesmo livro de histórias, olhou-o fixamente, acenou com a cabeça afirmativamente quando o investigador se propôs a ler para ele. Não respondeu a nenhum questionamento sobre o enredo, mesmo após a segunda leitura. Não respondeu se tinha entendido nem se queria escrever. 
Fora do contexto escolar, um mês antes, durante o exame neurológico, escreveu para o médico residente um texto significativo, ${ }^{3}$ contando sobre o animal de estimação. Embora não tivesse domínio da pontuação e de algumas convenções ortográficas, apresentou um volume significativo de linguagem, que, mesmo sendo de um gênero escolar, permitiu inferir que não havia alterações lingüísticas significativas.

\section{O cãozinho}

O cãozinho era muito bunitinho ele se chama pipo ele gosta de correr muito ele gosta de comer carne e gosta de correr atrás de mim ele é muito brabo e muito forte ele gosta dos filhotinhos ele defende eles ele tem muitos filhotinhos mais ele é muito peguissozo e muito sapeca. eu gosto muito dele

Investigada a história da criança, esse caso singular foi diagnosticado pelo neuropediatra como um caso de mutismo eletivo, um bloqueio raro de fala, psicologicamente determinado, que está presente em menos de $1 \%$ dos pacientes encaminhados para serviços de saúde infantil. No caso D. não se tratava de um problema que vinha sendo observado desde o início da aquisição da linguagem oral e sim após um trauma emocional, provocado pelo contato com a mãe biológica. Adotado legalmente com 2 dias por uma família de classe média, D., por ordem judicial, passou um mês com a mãe biológica que havia requerido sua guarda. A criança não se adaptou à nova forma de vida e adoeceu. Como chorava muito, a mãe biológica devolveu-o aos pais adotivos. Tendo ingressado na primeira série, freqüentou apenas 3 meses, retornando no ano seguinte.

Quando o menino estava na segunda série, a mãe biológica retornou e desta vez conseguira a guarda da criança nos fins de semana. D. passou a frequientar um bar de propriedade de sua mãe biológica, numa favela. Paralelamente à atitude de não falar, $D$. passou a não comer e não dormir, assistindo ao movimento do bar nas madrugadas. O pai estava preso, mas para o menino era dito que ele havia morrido.

3 É interessinte observar que os profissionais das ciências médicas envolvidos no traballho desse projeto passaram a levar em consideração a escrita da criança também como um parâmetro norteador para seus diagnósticos e durante entrevista com familiares ocupam a criança com produçĩo de textos, além de manifestarem considerável respeito ao trabalho do lingüista. 
Encaminhado para tratamento psicológico, D. passou a produzir oralmente algumas seqüências antes inexistentes e a acompanhar regularmente o processo escolar.

Sabedor do poder da linguagem escrita, sua única forma de contato fora do ambiente familiar, D. escreveu, um ano depois, uma carta de três páginas de papel almaço a um órgão estadual para denunciar a atitude de uma professora que, tendo diagnosticado intuitivamente o caso, chamara-o de "bebe quieto". Tendo havido um mal-entendido por parte da criança como "bibilóide quieto", o aluno ofende-se ao julgar que a professora o classificara como "debilóide quieto". Seu texto, agora escrito para alguém com alguma finalidade, não se apresenta telegráfico, mas com sentenças estruturadas de modo semelhante ao texto escrito durante a consulta e o gênero não é mais escolar.

\section{Caso 3: o caso P.H.}

O relato da história escolar de P.H., atualmente na quarta série, é pontuado por problemas escolares nas três escolas por que passou, tanto em Porto Alegre como em Curitiba. As queixas se resumiam à falta de compreenião de ordens e problemas escolares gerais. Suas respostas inadequadas durante o exame neurológico, descritas como idéias dissociadas, sem seqüência, com pausas freqüentes e lentidão, despertaram questionamentos.

Chama a atenção sua capacidade de decorar números telefônicos e sua preferência por guias rodoviários. Gosta de geografia e, apesar da facilidade de memorizar números, tem dificuldades para resolver operações matemáticas.

Diante da sugestão de escolher um livro para ler, recusou-se e preferiu pegar um jogo de alfabeto móvel que tinha sido usado para atividade com outra criança. Decidiu montar palavras aleatoriamente: Liane (a investigadora), urso, macaco, gato, janela. Parecia reproduzir listas de palavras, características de alfabetização tradicional.

Como a queixa da escola era de que P.H. não compreendia o que lhe era dito, sem ter sintomas de qualquer problema de audição, foram provocadas algumas estruturas para verificar se P.H. compreendia estruturas com sintaxe complexa como relativas e passivas, procedimento este diretamente decorrente dos estudos sobre agramatismo, previamente feitos por Gregolin-Guindaste (1996). Na primeira sessão, foi constatado que P.H. compreendia passivas, mas demonstrava problemas na compreensão de relativas.

Sobre a sentença "O filhote foi alimentado pela mãe", P.H. respondeu adequadamente às perguntas do investigador, mas as construções de P.H. não eram comuns: 
INV.: Quem alimentou o filhote?

P.H.: Quem alimentou, alimentou foi mãe.

INV.: A mãe? E o que a mãe fez com o filhote?

P.H.: Deu comida para ele.

Ao arranjar cartões com palavras recortadas para formar sentenças passivas, P.H. acerta algumas como "O bolo foi comido pelo menino", mas erra outras como "O brinquedo quebrado foi pela criança".

Para verificar a compreensão de relativas, o investigador apresentou várias sentenças sobre as quais fez perguntas e propôs repetição e montagem com cartões.

O dados abaixo revelam a capacidade cognitiva de P.H. para a compreensão de sentenças com relativa encaixada.

$O$ investigador apresentou a sentença " $O$ boi que os homens estão segurando é esperto" e pede para que seja lida.

P.H.: Os homens estão segurando que é o boi esperto.

O arranjo feito por P.H. demonstra sensibilidade para a cơncordância, pois ele agrupa a sequuência "boi esperto", mas mostra a dificuldade para o arranjo de estrutura contendo relativa, inclusive em situação de leitura.

Em outra estrutura com relativa, "O cachorro que abraça o homem é manso", arranjou com cartões a sequiência:

P.H.: O homem manso abraça que é o cachorro.

Questionado sobre a compreensão da estrutura, respondeu:

INV.: Quem é manso?

P.H.: O homem. 
Porém P.H. acerta as respostas sobre a estrutura "O guarda que vigia o bêbado é alto".

\author{
INV.: Quem é alto? \\ P.H.: O guarda. \\ INV.: E o que o guarda tá vigiando? \\ P.H.: Tá vigiando o bêbado.
}

Embora P.H. demonstre compreender algumas estruturas com relativas utilizando estratégias ainda a serem investigadas, a singularidade de seu caso confirma-se na dificuldade apresentada para recontar histórias por escrito.

O investigador leu para P.H. uma história de dois irmãos - Chico e Xande - que brigaram porque o primeiro zombou do segundo por ter errado palavras no ditado. Preocupado, Xande vai ao escritório e tenta fazer com letras, na máquina de escrever, o mesmo que a tia fazia com as notas no piano. Decora muitas palavras em várias línguas e o sucesso é atribuído a uma sopa de letrinhas que a mãe fizera.

P.H. tenta recontar por escrito, escreve duas sentenças sem problemas de convenção ortográfica e sem problemas de sintaxe, mas irrelevantes na constituição da significação da história.

Chico não deveria ter assustado por causa dele.

Mas você tem que dar uma bronca nele.

O caso P.H. continua sendo investigado, mas o que ficou claro até agora é que as aprovações escolares foram motivadas pela interiorização apenas do código escrito e não pelo domínio da linguagem em situações de uso.

\title{
Considerações
}

Retomando as reflexões de Coudry (1996) sobre o que é dado em neurolingüística e examinando o que está ocorrendo com os achados na linguagem de aprendizes de escrita, pode-se concluir que os dados peculiares de 
cada caso singular não são dados-exemplo, isto é, dados construídos por hipóteses prévias e para os quais a verificação empírica inexiste. Não são dados que apenas ilustram hipóteses e não são sentenças inventadas, embora possam constituir fonte para testes de teorias.

Também não são dados-evidência, como aqueles produzidos pela psicometria behaviorista, cuja quantificação está a serviço da linguagem concebida apenas como um código. Na neurolingüística moderna a quantificação constitui apenas um tipo de argumento, mas não ocupa o lugar nem se contrapõe ao dado-achado, cuja qualidade deve ser explicitada. Contar acertos e erros de P.H. pode ser parte da descrição, mas não da explicação para o problema.

Os dados e casos acima mencionados são achados. Na ânsia de obter novos dados de cada caso singular procede-se à experimentação ou testes não-tradicionais. Quando o dado é achado, estabelece-se um intervalo na pesquisa para que ações com a linguagem oral ou escrita tenham lugar. É o momento em que o investigador atua fazendo a criança produzir aquilo que o achado havia mostrado como o ponto do problema. Da parceria investigador e criança são obtidos outros dados, que arquivados formam um corpus que permite o acompanhamento longitudinal e a constatação do progresso ou a confirmação de que o caso singular exige retomadas explicativas.

O trabalho que se desenvolve sob as circunstâncias relatadas aqui considera a neurolingüística como um lugar capaz de fazer análise lingüística de dados patológicos e como um domínio de atuação sobre dificuldades lingüísticocognitivas. Nele é impossível não ancorar a prática em princípios teóricos.

Os dados e casos acima mencionados ilustram a dimensão de pesquisas ainda por fazer. Uma vez que estes achados não se situam nas preferências da psicolingüística e não interessam ao lingüista não preocupado com dados patológicos, a tarefa está destinada aos que aceitarem o desafio de desenvolver a neurolingüística. Trata-se de um trabalho inspirado no acompanhamento de patologias de linguagem em adultos cérebro-lesados, que toma rumos próprios ao investigar casos singulares e regulares de casos de problemas de linguagem em aprendizes de escrita.

\section{Procedimentos}

No estudo de casos-problema de linguagem aqui apresentados, foram quatro os procedimentos, adotados conforme o tipo.

1) Quando a criança já apresenta alguma iniciação na escrita, isto é, consegue compreender o engendramento das letras, fazendo alguma relação 
grafema-fonema, e sua escrita autônoma apresenta alguma legibilidade, os dados de escrita passam a ser investigados. O progresso da criança passa a ser focalizado a cada sessão com o investigador experiente que, além de procurar fazer a criança constituir-se num aluno sujeito, procura formar-lhe, via conscientização, as funções mentais superiores, conforme Luria (1979). Sem desenvolvimento da percepção, da memória, da atenção, da linguagem e da própria consciência, as tarefas escolares coletivas ficam afetadas. Os três casos estudados por Gusso (1996) e a maioria das crianças acompanhadas enquadram-se nessa descrição.

Este tem sido o procedimento para a maioria dos casos que, à primeira vista classificados como dislexia, colocam essa síndrome em discussão na lingüística.

2) Quando nenhum dado de escrita autônoma com alguma relação grafema-fonema for obtido, investiga-se a oralidade para detectar os mistérios e os bloqueios de aquisição de escrita. Primeiramente é investigada a capacidade da criança de narrar eventos vividos e recontar histórias ficcionais. Se nenhuma alteração significativa for observada na oralidade, esta é dada como adequada. Portanto, se a criança não apresentar problema cognitivo em relação à oralidade, que já é um simbolismo de primeira ordem, resta explicar por que não consegue apreender a escrita, que é a representação da fala, um simbolismo agora de segunda ordem, isto é, representação de outra representação.

Em casos como estes, comuns em escolas especiais, é preciso rever a avaliação da linguagem oral e inspecionar o modo como a escrita está sendo ensinada. Se a linguagem usada nas atividades de escrita estiver despida da significação, questões de ordem metodológica relacionadas à concepção de linguagem podem estar envolvidas. Os dois primeiros casos relatados (J. e R.) foram investigados segundo esse procedimento.

3) Quando a criança já se iniciou na escrita, mas apresenta problemas na produção de textos mais graves do que os que a escola considera triviais, investiga-se a escrita para nela interferir e provocar no aprendiz operações epilingüísticas de autocorreção, operações lingüísticas de acréscimos, supressões, deslocamentos e substituições visando à reestruturação de textos e a formação do produtor de escrita clara e organizada. Estes casos são numerosos e considerados regulares.

Quando os mistérios permanecem, provoca-se a produção de determinadas estruturas e são feitos alguns testes não-tradicionais. É o que está sendo feito com o caso P.H.

4) Em casos raros em que a fala não se manifesta e sim a escrita, esta passa a ser uma via de mão dupla para servir como forma de interlocução e de meio para diagnóstico da capacidade lingüística. É o que foi feito no caso D. 


\section{Conclusão}

O interesse pela linguagem em casos de aprendizes de escrita apontados como problemas, uns patológicos, obriga o pesquisador a fazer um trabalho de buscas teóricas para amparar os diagnósticos e indicar pistas para a solução de problemas. Na maioria dos casos, as crianças não apresentam problemas neurológicos, nem lingüistico-cognitivos, e nesses casos o trabalho do lingüista é o de argumentar contra a rotulagem dada por testes psicológicos, após análise dos dados de oralidade e escrita.

Trata-se de um trabalho em neurolingüística no qual os exames neurológicos e psicológicos clássicos, normalmente feitos na instituição, independentemente da investigação linguiística, compõem o trabalho multidisciplinar necessário para o trabalho com sujeitos. São motivados pela busca de argumento de autoridade, mas somam o ônus da geração de questões epistemológicas diversas referentes às diferentes disciplinas envolvidas. Isto coloca desafios para a pesquisa, mas também controvérsias necessárias para que a ciência se desenvolva.

\section{RESUMO}

O objetivo deste artigo é apresentar alguns casos patológicos singulares de linguagem oral e escrita em crianças em idade escolar. Os procedimentos usados para diagnóstico são diferentes dos tradicionais. A orientação teórica da neurolingüística moderna forneceu metodologia para a coleta de dados.

Palavrus-chave: neurolingüistica, casos patológicos, aquisição de linguagem escrita.

\section{ABSTRACT}

The aim of this article is to present some singular patological cases of written and oral language in school chidren. The procedure used for diagnosis is different from traditional ones. The theoretical orientation of the modern neurolinguistics provided the methodology in order to gather data.

Key words: neurolinguistics, pathological cases, written language acquisition. 


\section{REFERÊNCIAS BIBLIOGRÁFICAS}

ABAURRE, M. B. Os estudos lingüísticos e a aquisição da escrita. ln: CASTRO, M. F. P. (Org.). O método e o dado no estudo da linguagem. Campinas: Editora da Unicamp, 1996.

COUDRY, M. I. H. O diário de Narciso: discurso e afasia. Sāo Paulo: Martins Fontes, 1988.

O que é dado em neurolingüística. In: CASTRO, M. F. P. (Org.). $O$ método e o dado no estudo da linguagem. Campinas: Editora da Unicamp, 1996.

FRANCHI, C. Linguagem: atividade constitutiva. In: Cadernos de Esttudos Lingiuisticos, Campinas, Unicamp/lEL, v. 22, p. 9-39, 1992.

GERALDI, J. W. Portos de passagem. São Paulo: Martins Fontes, 1991.

GREGOLIN-GUINDASTE, R. M. Agramatismo: um estudo de caso em português. Campinas, 1996. Tese de Doutorado - Unicamp.

GUSSO, A. M. Análise lingiḯstica: um acompanhamento longitudinal de três casos de aquisiç̧ão de escrita. Curitiba, 1996. Dissertação de Mestrado - UFPR.

LURIA, A. R. Curso de psicologia geral. Rio de Janeiro: Civilização Brasileira, 1979.

MAYRINK-SABINSON, M. L. A produção escrita da criança e sua avaliação. In: Cadernos de Estudos Lingüisticos, Campinas, Unicamp/lEL, n. 24, p. 19-33, 1993.

PAN, M. Infância e discurso: contribuições para avaliação da linguagem. Curitiba, 1995. Dissertação de Mestrado - UFPR.

PERRONE, M. C. Desenvolvimento do discurso narrativo. São Paulo: Martins Fontes, 1992. 